\title{
Polymer based organic solar cells using ink-jet printed active layers
}

\author{
T. Aernouts, ${ }^{\text {a) }}$ T. Aleksandrov, C. Girotto, J. Genoe, and J. Poortmans \\ Polymer and Molecular Electronics, SOLO Department, IMEC, Kapeldreef 75, B-3001 Leuven, Belgium
}

(Received 26 October 2007; accepted 13 December 2007; published online 25 January 2008)

\begin{abstract}
Ink-jet printing is used to deposit polymer:fullerene blends suitable as active layer for organic solar cells. We show that merging of separately deposited ink droplets into a continuous, pinhole-free organic thin film results from a balance between ink viscosity and surface wetting, whereas for certain of the studied solutions clear coffee drop effect occurs for single droplets; this can be minimized for larger printed areas, yielding smooth layers with minimal surface roughness. Resulting organic films are used as active layer for solar cells with power conversion efficiency of 1.4\% under simulated AM1.5 solar illumination. (C) 2008 American Institute of Physics.
\end{abstract}

[DOI: $10.1063 / 1.2833185]$

Polymer based organic solar cells ${ }^{1-3}$ have gained more and more interest over the past years, as reflected by a steady increase in the reported power conversion efficiency $(\mathrm{PCE}){ }^{4,5}$ Especially devices with an active layer of poly $(3-$ hexylthiophene) (P3HT) mixed with fullerene derivatives have been extensively studied, with improved understanding of the general working principles of these bulk heterojunction solar cells. ${ }^{6,7}$ With PCE values $\sim 5 \%$, it is strongly believed that such polymer based organic devices can offer a cost-effective alternative to the market dominating $\mathrm{Si}$ photovoltaics. $^{8,9}$ Thin film deposition from solution at relatively low temperatures results in limited material usage and low fabrication cost for the organic solar cells. Though, to evolve from lab-scale demonstrator devices to real large-area deposited photovoltaic modules, the introduction of adequate processing techniques is required. ${ }^{10}$ Printing technologies have attracted considerable attention for organic electronics due to their potentially high volume and low cost processing. Additionally, printing allows deposition of active materials on specific areas of the substrate, contrary to, e.g., spin coating. Incorporation of photovoltaic devices onto substrates containing already other components or production of monolithic organic photovoltaic modules is thereby facilitated substantially. ${ }^{11-16}$

In this letter, we demonstrate the use of ink-jet printing for the deposition of the active layer of a bulk heterojunction solar cell, consisting of a P3HT: fullerene blend. Since inkjet printing is a method of selectively depositing separately generated droplets of precise volume, ${ }^{17}$ continuous films can only be formed by the merging of these separately deposited droplets on the substrate. Control over the ink-jet process yields films that are pinhole-free and therefore suitable as active layer in organic solar cells. Balanced ink viscosity and surface wetting yields smooth layers with minimal surface roughness. Power conversion efficiency of $1.4 \%$ under simulated AM1.5 solar illumination is obtained for devices fabricated in air.

Solar cell devices are fabricated on glass substrates $\left(1.25 \times 1.25 \mathrm{~cm}^{2}\right)$ covered with indium tin oxide (ITO) (Merck Display Technologies, sheet resistance $<20 \Omega / \square$ ) which was patterned by standard UV photolithography. Afterward, the substrates were thoroughly cleaned by ultra-

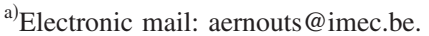

sonication in subsequent detergent and acetone baths for $10 \mathrm{~min}$. The cleaning cycle was finished by submerging them in hot isopropyl alcohol, washing in de-ionized water, and drying under nitrogen flow. Prior to depositing a poly (3,4-ethylenedioxythiophene):poly(stryrenesulfonate) (PEDOT:PSS) (Baytron P AI4083, HC Starck) layer by spin coating, an oxygen plasma treatment $(100 \mathrm{~W}, 10 \mathrm{~min}$.) was carried out on the substrates. Drying of the PEDOT:PSS layer was done on a hotplate at $120^{\circ} \mathrm{C}$ for $10 \mathrm{~min}$ in air.

The active layer resulted from an ink-jet printed solution of poly(3-hexylthiophene) (P3HT) (Rieke Metal, Inc.) and $(6,6)$-phenyl $\mathrm{C}_{61}$-butyric acid methyl ester (PCBM) (Solenne $\mathrm{BV})$ mixed in a $1: 1$ ratio by weight. These compounds have been dissolved in a 1:1 volume mixture of chlorobenzene (CB) with the high boiling point solvent tetrahydronaphthalene (tetraline or THN) to prevent clogging of the printhead. Different ratios of polymer content to the total solvent volume have been subject of investigation. Fabrication of the active layer by ink-jet printing was done in air. Afterward, the samples were loaded into a vacuum evaporation setup (pressure below $10^{-6}$ Torr) to deposit $\mathrm{Al}$ back side electrodes $(100 \mathrm{~nm})$ through a shadow mask. In this way, on one substrate, several solar cell devices with active areas $\sim 0.03 \mathrm{~cm}^{2}$ are fabricated.

In this work, results are based on the piezoelectric principle using a Fujifilm Dimatix DMP-2831 Materials Printer. Jetting of the fluid is controlled by a voltage pulse to deform the piezoelectric actuator in the ink cavity and eject a drop from the nozzle, as represented in Fig. 1. Hence, the action of the pressure wave is to overcome the surface tension at the ink/air interface which normally retains the fluid at the nozzle orifice. Only above some critical value, the protruding

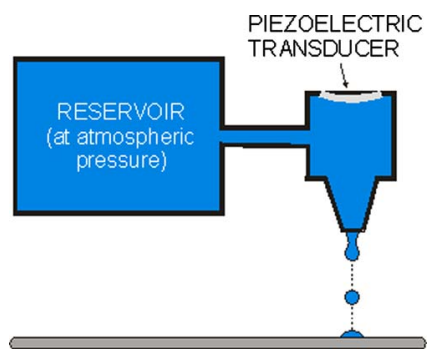

FIG. 1. (Color online) Schematic representation of the piezoelectric ink-jet printing technique. 
TABLE I. Viscosity, surface tension, and boiling points of solvents and solutions of P3HT:PCBM.

\begin{tabular}{cccc}
\hline \hline Liquid & $\begin{array}{c}\text { Viscosity } \\
(\mathrm{mPa} \mathrm{s})\end{array}$ & $\begin{array}{c}\text { Surface tension } \\
\left(\mathrm{mN} \mathrm{m}^{-1}\right)\end{array}$ & $\begin{array}{c}\text { Boiling point } \\
\left({ }^{\circ} \mathrm{C}\right)\end{array}$ \\
\hline Chlorobenzene & 0.8 & 33.6 & 130 \\
Tetraline & 2.1 & 33.2 & 207 \\
THN/CB $(1 / 1)$ & 1.7 & 33.3 & \\
$1 \%$ & 2.3 & 35.2 & \\
$2 \%$ & 3.9 & 35.2 & \\
$3 \%$ & 6.1 & 35.2 & \\
\hline \hline
\end{tabular}

liquid finger will pinch off to eject a droplet. Viscous pressure loss in the nozzle in combination with the mechanics and dimensions of the ink chamber and nozzle will determine this critical value. ${ }^{18}$

In Table I, the results from viscosity and surface tension measurements are presented. The $1 \%, 2 \%$, and $3 \%$ solutions refer to weight percentages of P3HT:PCBM of ratio 1:1 in a solvent blend of $1: 1$ by volume of tetraline and chlorobenzene.

The surface tension values for the pure solvents are those found in the literature. For the mixed tetraline and chlorobenzene solvent and the P3HT:PCBM solutions, the pending drop method is used to measure the surface tension, using a hypothermic needle connected with the motor syringe of an OCA-20 contact angle measurement system (DataPhysics $\mathrm{GmbH}$ ). Since for the pure solvents surface tension values are very similar, it is not surprising that for the solvent mixture of tetraline and chlorobenzene a value in the same order is obtained. This also indicates a high miscibility of the two solvents with each other. Upon addition of P3HT and PCBM, a slight increase can be observed but no further change is induced for increasing concentration of the solid compounds. The dissolved organic materials have no strong influence on the interfacial energy of the solvents due to their strong nonpolar character.

On the contrary even in small quantities the added polymer:fullerene mixture increases the viscosity significantly when dissolved in the solvents. The viscosity is measured with a micro-Ostwald viscometer (Schott Instruments $\mathrm{GmbH})$ with an inner capillary diameter of $0.6 \mathrm{~mm}$.

While surface tension values are relatively close to each other, the dynamic viscosity raises with several times from the pure solvent to the $3 \%$ solution. This is mainly due to interactions of the P3HT polymer chains with the solvents or with each other, already strong even when presented in small quantities.

After studying the quality of the ejected drop, the interaction between the printed material and the substrate is taken under consideration. Thickness profiles of printed drops and films were studied by means of Wyko NT3300 DMEMS Optical Profilometer (VEECO).

Surface profiles of ink-jet printed droplets on the substrate surface are shown in Figs. 2(a) and 2(b). For both $1 \%$ and $2 \%$ P3HT:PCBM solutions, a base width of the drops in the order of $120 \mu \mathrm{m}$ is obtained. With a printhead nozzle diameter of $21 \mu \mathrm{m}$, it means that the jetted volume spreads well over the substrate. Surface wettability is studied by contact angle measurements to evaluate the influence of the surface on the spreading of a liquid over it. Pure chlorobenzene and tetraline as well as drops of the solvent mixture and the Downloaded 02 Mar 2008 to 146.103.254.11. Redistribution subject

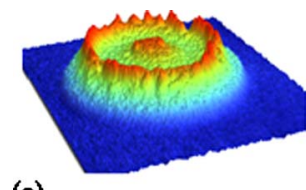

(a)

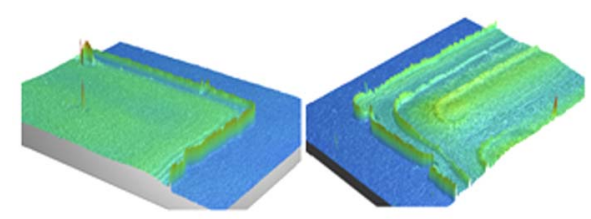

(c)



(b)

(d)
FIG. 2. (Color online) Three-dimensional optical images displaying inkjet printed P3HT:PCBM features: (a) $126 \times 114 \mu \mathrm{m}^{2}$ area with a $1 \%$ drop, (b) $110 \times 145 \mu^{2}$ area with a $2 \%$ drop, (c) $2.3 \times 1.8 \mathrm{~mm}^{2}$ area with a $1 \%$ surface, and (d) $2.3 \times 1.8 \mathrm{~mm}^{2}$ area with a $2 \%$ surface.

P3HT:PCBM solutions were deposited on glass and ITO surfaces, cleaned according to the procedures described above. Also deposition on ITO substrates covered with a PEDOT:PSS layer was studied. High wettability of all surfaces by all liquids was observed since in all cases contact angles clearly below $10^{\circ}$ were measured. So, surface interaction is not determined by the solute or its concentration in the solvents but most strongly by the solvent physical properties itself.

On the contrary, the overall profiles differ substantially for both compositions. Strong ring formation during drying occurred for the $1 \%$ concentrated solution, which is strongly minimized for the $2 \%$ solution. A central profile height of $\sim 120 \mathrm{~nm}$ for the $1 \%$ and $\sim 160 \mathrm{~nm}$ for the $2 \%$ concentrated solution after drying is shown. For the latter, a uniform plateau is formed with only decreasing thickness at the edges of the drop. The $1 \%$ solution resulted in a central peak clearly separated from the droplet edges by dips of $\sim 40 \mathrm{~nm}$. This ring formation with an accumulation of solute material at the droplet edge is a commonly observed phenomenon, known as the coffee drop effect. ${ }^{19}$ It is due to the combined action of an increased evaporation rate at the edge and contact line pinning due to surface irregularities and solute deposition.

Printing of continuous lines or surfaces alters the profiles substantially, as shown in Figs. 2(c) and 2(d). As explained before, wetting of the substrate surface with the printed solution is easily achieved, resulting in good merging of adjacent deposited droplets. For the 1\% P3HT:PCBM solution, this yields a continuous, pinhole-free, smooth layer. Only some additional solute concentration occurs at the edges of the full surface. Edge height values are 1.5-2 times bigger than the average thickness of the film, which is $\sim 160 \mathrm{~nm}$. For the higher concentrated solutions, viscous forces limit the spreading of material over the full area, resulting in less uniform surfaces with solid material accumulation not only restricted to the edges of the surface.

An organic bulk heterojunction solar cell with an ink-jet printed film of the $1 \%$ P3HT:PCBM solution has been fabricated. Current-density versus voltage $(J-V)$ characterization has been performed in the dark and under simulated illumination using an Agilent 4156C parameter analyzer and a LOT-Oriel 1000-W xenon arc lamp with AM 1.5 D filters. Calibration was performed by a KG3 band pass filter and a calibrated silicon photodetector. The resulting characteristics are shown in Fig. 3. The rectification of the device in the to AIP license or copyright; see http://apl.aip.org/apl/copyright.jsp 


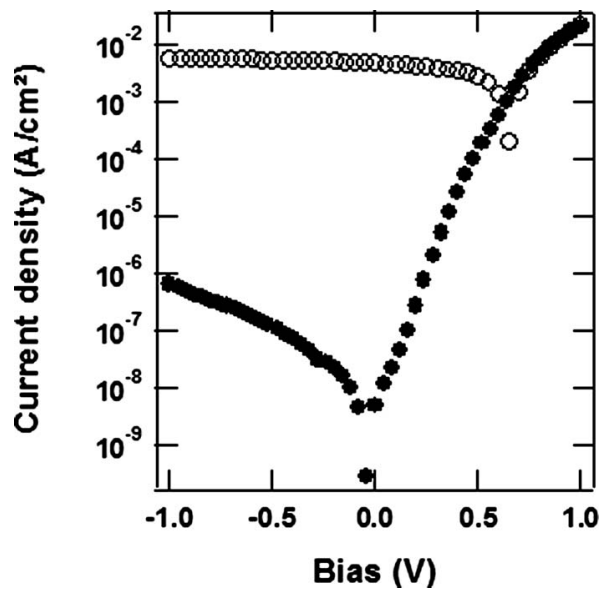

FIG. 3. Current density versus voltage characteristics for the solar cell with an inkjet printed active layer of $1 \%$ P3HT:PCBM, operated in the dark (filled circles) and under simulated AM1.5 illumination of $100 \mathrm{~mW} / \mathrm{cm}^{2}$ (open circles). The short-circuit current, open-circuit voltage, fill factor and power conversion efficiency are $4.67 \mathrm{~mA} / \mathrm{cm}^{2}, 660 \mathrm{mV}, 0.46$, and $1.4 \%$, respectively.

dark is over 3000 at $\pm 1 \mathrm{~V}$. This indicates good diode behavior, especially the low reverse bias current reveals pinholefree film formation by the ink-jet printing technique. This is also demonstrated by the performance under illumination. Especially the open-circuit voltage and fill factor, which are $660 \mathrm{mV}$ and 0.46 , respectively, indicate no substantial losses due to electrical shunting between top and bottom contacts. The short-circuit current is $4.67 \mathrm{~mA} / \mathrm{cm}^{2}$, yielding a power conversion efficiency of $1.4 \%$.

The slight offset at zero bias in the characteristic measured under dark conditions indicates that deep trap states for injected carriers at an interface are present, as described by Brutting et $a l .{ }^{20}$ Such an effect can be expected since the active layer is deposited in air by the ink-jet printing process. Therefore, it was not possible to fully exclude oxygen, humidity and moisture to be present either at the anode or cathode interface. Furthermore, lower power conversion efficiency obtained here by ink-jet printing than typically described for spin coated devices could be partially attributed to this. Also, the processing conditions have not yet been optimized here to obtain the most favorable nanomorphology for the active layer. This could be obtained by controlled solvent evaporation or by optimized solvent mixture ratios, which are objects of continued study.

Conclusively, we have demonstrated the fabrication of organic solar cell devices with a polymer:fullerene active layer deposited by ink-jet printing. Continuous, pinhole-free organic thin films are formed due to the merging of the separately deposited ink droplets. A balance between ink viscosity and surface wetting yielded smooth P3HT:PCBM layers with minimal surface roughness, resulting in devices with PCE of $1.4 \%$ under simulated AM1.5 solar illumination. The results demonstrated here illustrate that ink-jet printing can be a low cost processing technique facilitating substantially the incorporation of photovoltaic devices into electronic applications or production of monolithic organic photovoltaic modules. It is believed that optimization of active layer morphology by postproduction treatments, solvent evaporation control, or adequate solvent mixture ratios can result in performances comparable to those of spin coated devices.

The authors would like to acknowledge the SBO-project 030220 "NANOSOLAR" funded by the Institute for the Promotion of Innovation by Science and Technology in Flanders (IWT). Furthermore, D. Vanhaeren is highly acknowledged for the optical profilometry imaging.

${ }^{1}$ E. Bundgaard and F. C. Krebs, Sol. Energy Mater. Sol. Cells 91, 954 (2007).

${ }^{2}$ S. Günes, H. Neugebauer, and N. S. Sariciftci, Chem. Rev. (Washington, D.C.) 107, 1324 (2007).

${ }^{3}$ B. P. Rand, J. Genoe, P. Heremans, and J. Poortmans, Prog. Photovoltaics 15, 659 (2007).

${ }^{4}$ S. E. Shaheen, C. J. Brabec, N. S. Sariciftci, F. Padinger, T. Fromherz, and

J. C. Hummelen, Appl. Phys. Lett. 78, 841 (2001).

${ }^{5}$ F. Padinger, R. S. Rittberger, and N. S. Sariciftci, Adv. Funct. Mater. 13, 1 (2003).

${ }^{6}$ P. Vanlaeke, A. Swinnen, I. Haeldermans, G. Vanhoyland, T. Aernouts, D. Cheyns, C. Deibel, J. D'Haen, P. Heremans, J. Poortmans, and J. Manca, Sol. Energy Mater. Sol. Cells 90, 2150 (2006).

${ }^{7}$ Y. Kim, S. Cook, S. M. Tuladhar, S. A. Choulis, J. Nelson, J. R. Durrant, D. D. C. Bradley, M. Giles, I. McCulloch, C.-S. Ha, and M. Ree, Nat. Mater. 5, 197 (2006).

${ }^{8}$ C. J. Brabec, Sol. Energy Mater. Sol. Cells 83, 273 (2004).

${ }^{9}$ M. C. Scharber, D. Mühlbacher, M. Koppe, P. Denk, C. Waldauf, A. J. Heeger, and C. J. Brabec, Adv. Mater. (Weinheim, Ger.) 18, 789 (2006).

${ }^{10}$ M. Al-Ibrahim, H. K. Roth, and S. Sensfuss, Appl. Phys. Lett. 85, 1481 (2004).

${ }^{11}$ F. C. Krebs, M. Biancardo, B. Winther-Jensen, H. Spanggard, and J. Alstrup, Sol. Energy Mater. Sol. Cells 90, 1058 (2006).

${ }^{12}$ S. E. Shaheen, R. Radspinner, N. Peyghambarian, and G. E. Jabbour, Appl. Phys. Lett. 79, 2996 (2001).

${ }^{13}$ T. Aernouts, P. Vanlaeke, W. Geens, J. Poortmans, P. Heremans, S. Borghs, R. Mertens, R. Andriessen, and L. Leenders, Thin Solid Films 451-452, 22 (2004).

${ }^{14}$ T. Aernouts, P. Vanlaeke, J. Poortmans, and P. Heremans, Proc. SPIE 5464, 252260 (2004).

${ }^{15}$ F. C. Krebs, J. Alstrup, H. Spanggaard, K. Larsen, and E. Kold, Sol. Energy Mater. Sol. Cells 83, 293 (2004).

${ }^{16}$ F. C. Krebs, H. Spanggaard, T. Kjaer, M. Biancardo, and J. Alstrup, Mater. Sci. Eng., B 138, 106 (2007).

${ }^{17}$ B.-J. de Gans, P. C. Duineveld, and U. Schubert, Adv. Mater. (Weinheim, Ger.) 16, 203 (2004).

${ }^{18}$ N. Reiss, C. Ainsley, and B. Derby, J. Appl. Phys. 97, 094903 (2005).

${ }^{19}$ R. D. Deegan, O. Bakajin, T. F. Dupont, G. Huber, S. R. Nagel, and T. A. Witten, Nature (London) 389, 827 (1997).

${ }^{20}$ W. Brutting, H. Riel, T. Beierlein, and W. Riess, J. Appl. Phys. 89, 1704 (2001). 